\title{
Revista

\section{A Folha de Boa Vista e a desintrusão na Terra Indígena Raposa Serra do Sol}

\section{Folha de Boa Vista and removing invaders from Raposa Serra do Sol}

\section{BÁRBARA HELLER}

Professora do Mestrado em Comunicação na Universidade Paulista - UNIP.

$<$ b.heller@terra.com.br>

\section{WENYA ALECRIM}

Professora do Instituto de Ensino Superior de Rio Verde - IESRIVER e Faculdade de Ciências Sociais e Tecnológicas - Facitec.

<wenyaalecrim@hotmail.com>

\section{RESUMO}

Em abril de 2009, o Supremo Tribunal Federal confirmou a homologação contínua da Terra Indígena Raposa Serra do Sol, em Roraima, decisão que obrigou a população não indígena, constituída por pequenos colonos e grandes exportadores de arroz, a sair da região. Aos quase 20 mil índios que disputavam o direito sobre a terra, de aproximadamente 1,7 milhão de hectares, coube comemorar. A Folha de Boa Vista (FBV), um dos maiores jornais do Estado de Roraima (Brasil), participou ativamente dessa disputa em suas edições diárias. Neste artigo, mediante o instrumental da Análise do Discurso, analisamos 23 reportagens publicadas por esse jornal ao longo de 2009, a fim de compreender em que medida ele reforçou ou resistiu ao poder hegemônico, suas estratégias discursivas, as mediações e representações dos grupos sociais envolvidos.

Palavras-chave: Discurso; Mídia; Representações.

\section{ABSTRACT}

In April 2009, the Supreme Court of Justice confirmed the continuous approval of Terra Indígena Raposa Serra do Sol, in Roraima, decision that forced the non-indigenous population, constituted by small settlers and great rice exports, to leave the area. The 20 thousand indians that fought for the right over the land, of approximately 1,7 million hectares, celebrated the decision. Folha de Boa Vista (FBV), one of the greatest newspapers of the state of Roraima (Brazil), participated actively of this dispute in its daily editions. In this article, using the Discourse Analysis, we analyzed 23 reports published by this newspaper during the year of 2009, in order to understand how it reinforced or resisted to hegemonic power, its discourse strategies, the mediations and representations of the social groups involved. 
- ntender o processo final de desintrusão da Terra Indígena Raposa Serra do Sol ـ(TIRSS), localizada em Roraima (Brasil), é uma tarefa que exige do pesquisador um posicionamento crítico, pois a terra, disputada por não-índios e índios, foi palco de discussões políticas, agressões físicas e disputas ideológicas por mais de 30 anos. Finalmente, em 30 de abril de 2009, o Supremo Tribunal Federal determinou que todos os não-índios fossem imediatamente retirados da TI.

O termo "desintrusão", pouco usual em outros lugares, em Roraima é corriqueiro. $\mathrm{Na}$ verdade, ele significa, em linhas gerais, a ação de retirar de determinada área alguém que a invadiu. Vários atores sociais estavam envolvidos na desintrusão da TIRSS em Roraima: desde líderes indígenas, que defendiam veementemente a sua demarcação em ilhas, o que permitiria que arrozeiros e pequenos colonos que habitavam a região havia anos continuassem na reserva, em um convívio a que eles mesmos chamavam de "harmonioso", até outras lideranças, também indígenas, que pediam a retirada de todos não índios da reserva. Nesse mesmo cenário, encontramos arrozeiros, que temiam perder suas terras depois de anos de conquista e trabalho, e parte da população do Estado que os apoiava.

Com tantos discursos contraditórios sobre o mesmo tema, nos propusemos a analisar neste artigo as maneiras pelas quais a mídia local noticiou o processo final da retirada dos não-índios, as mediações e representações dos grupos sociais envolvidos diretamente (indígenas, arrozeiros e políticos/fontes oficiais). Para isso, trabalhamos com o jornal Folha de Boa Vista (FBV), o maior e mais antigo periódico de Roraima (RR). Entre as 170 reportagens (também conhecidas como matérias) publicadas sobre o tema, apresentamos neste artigo a análise de 23 textos que tiveram chamada na capa do jornal, mas reproduzimos trechos de quatro deles, por economia de espaço. Em algumas passagens de nossa análise, no entanto, sentimos necessidade de recorrer às matérias que não foram transcritas, a fim de contextualizar melhor 
o corpus selecionado e tornar mais claros os conceitos que deram suporte a nossas hipóteses.

Como ferramenta teórica, apoiamo-nos na Análise do Discurso, (AD), especialmente nos conceitos do filósofo Mikhail Bakhtin - enunciado (contexto de produção), enunciador (aquele que produz um discurso), palavra - e também em Dominique Maingueneau, no tocante à noção de contexto.

Mikhail Bakhtin salienta que todos os processos de comunicação são dialógicos, isto é, são atravessados pela palavra do outro, que por sua vez também é atravessada, e assim sucessivamente. Mais ainda: que a linguagem ocupa um papel fundamental nos processos sociais, pois como não existe acesso direto à realidade - "o real apresenta-se para nós sempre semioticamente, ou seja, linguisticamente" (Fiorin, 2008, p. 19) - ela constitui os enunciados que marcam uma posição dos sujeitos enunciadores:

[...] o enunciado ocupa uma posição definida em uma dada esfera da comunicação, em uma dada questão, em um dado assunto, etc.. É impossível alguém definir sua posição sem relacioná-la com outras posições. Por isso, cada enunciado é pleno de variadas atitudes responsivas a outros enunciados de dada esfera da comunicação discursiva."

(Bakhtin, 2003, p. 297)

Para Dominique Maingueneau, o contexto que cerca o fato desempenha um papel muito importante e é fornecedor de dados que permitem não só desfazer ambiguidades, mas também compreender melhor os enunciados. Nesse sentido, segundo Beth Brait (2007), é necessário "olhar para fora do texto" ou, como também sugere Michael 
Foucault, enfrentar a "massa de traços" verbais e extraverbais que povoa o texto e aponta para fora dele, vinculando, social e historicamente, sujeito, vida e linguagem.

Embora o homem seja no mundo o único ser que fala, não constitui de modo algum ciência humana o conhecer as mutações fonéticas, o parentesco das línguas, a lei das derivações semânticas; em contrapartida, poder-se-á falar de ciência humana desde que se procure definir a maneira como os indivíduos ou os grupos concebem as palavras, utilizam a sua forma e o seu sentido, compõem discursos reais, neles mostram e ocultam o que pensam, dizem, sem que talvez tenham consciência disso, mais ou menos do que pretendem dizer, deixam, em todo caso, desses pensamentos, uma massa de traços que é necessário decifrar e restituir tanto quanto é possível à sua vivacidade representativa."

(Foucault [1966], pp. 458-459 apud Brait, 2007)

Isso posto, pretendemos, dentro dos limites permitidos em um artigo, "decifrar e restituir a veracidade representativa" dos enunciadores nas 23 reportagens publicadas pela Folha de Boa Vista.

\section{Apresentando o corpus}

A FBV foi inaugurada em 1983. Passou por várias mãos, até se tornar propriedade do ex-governador do, então, Território de Roraima, Getúlio Cruz. Hoje é a filha, Paula Cruz, quem coordena a empresa (Soares apud Lima, 2008, p. 30). O veículo é visto no Estado como o jornal de maior credibilidade, tanto pelos anos de atuação, quanto pela linha editorial desenvolvida. 
As 23 reportagens que agrupamos neste artigo pertencem a um mesmo gênero textual e buscam, por definição, informar, apresentando "apenas" os fatos como eles aconteceram. A reportagem, rezam os manuais, responde às questões "como?" e "por quê?"; no entanto, as conclusões cabem ao leitor (Zancheta, 2006).

Menos do que teorizar sobre cada um dos gêneros textuais - "tipos de enunciados relativamente estáveis, caracterizados por um conteúdo temático, uma construção composicional e um estilo" (Fiorin, 2008, p. 61) - nosso objetivo é compreender, numa perspectiva bakhtiniana, como os textos de, um mesmo gênero, da FBV, foram construídos e que circunstâncias permearam o enunciador.

Fiorin (2008), um dos estudiosos de Bakhtin, esclarece ainda que, para o filósofo russo, o ponto de partida para compreender os gêneros textuais está na análise da linguagem entrelaçada com as atividades humanas, por compreender que não há produção dos textos fora das ações.

Para Martín-Barbero (2003, p. 187), outro teórico em que nos apoiamos, os meios de comunicação estabelecem uma mediação institucional com o mercado, que reorienta, rearticula a intencionalidade do escritor. Essa mediação, por vezes, interfere no que foi escrito, na seleção do que é notícia ou não, ou ainda do que vai aparecer na capa ou no próprio corpo do jornal, produzindo sentidos diferentes.

O olho do jornalista é, ou pelo menos deveria ser, o olho da sociedade. No campo acadêmico, o olho do jornalista é "educado" para ter visão crítica e social. Pierre Bourdieu (1997, p. 25) diz que esses profissionais possuem uma espécie de óculos especiais que veem, destacam algumas coisas e anulam outras.

Em nosso corpus, observamos alguns discursos que se repetiram, por isso tabulamos as reportagens em três grandes eixos temáticos: Lutadores e injustiçados, inversão de papeis?; Conflito e Reforço às tradições $x$ desenvolvimento: da parixara ao forró. Como as reportagens analisadas foram escritas por repórteres mulheres, usaremos o gênero 
feminino, a repórter, para falar de sua autoria, mas não entraremos no mérito da discussão do fato de se tratar ou não de uma escrita feminina em oposição a uma masculina.

Tabela 1 - Exemplos enumerados por ordem cronológica de publicação

\begin{tabular}{ccl}
\hline$N^{\circ}$ & Dia publicado & \multicolumn{1}{c}{ Título (no interior do jornal) } \\
01 & $28 / 01 / 2009$ & Índios ocupam prédio da Funai e mantêm administrador refém durante seis horas \\
02 & $19 / 03 / 2009$ & Suspensão temporária de julgamento não acirra ânimos em Surumu \\
03 & $20 / 03 / 2009$ & Sodiur alerta para conflito entre índios \\
04 & $12 / 05 / 2009$ & Produtora diz que multa levará à falência \\
\hline
\end{tabular}

\section{Lutadores e injustiçados: inversão de papeis?}

Na maioria dos textos analisados os indígenas foram representados incitando conflitos ou afirmando que não mediriam esforços para ter a terra somente para si. Os arrozeiros, por sua vez, ganharam o discurso dos injustiçados. Em boa parte das reportagens reclamaram do processo demarcatório e afirmaram que iriam à falência.

Na reportagem $\mathrm{n}^{\mathrm{o}}$ 04, não só o corpo do texto, mas também, o título incitam à comoção do leitor: Produtora diz que multa levará à falência. Na sequência, o primeiro parágrafo mostra a situação praticamente precária em que se encontravam os arrozeiros:

A empresária Regina Barili, proprietária da marca de arroz Tio Ivo, procurou a Folha para narrar a situação de desamparo em que estão vivendo os rizicultores que há 12 dias deixaram as fazendas que ocupavam na terra indígena Raposa Serra do Sol, ao norte de Roraima."

(Folha de Boa Vista, 12/05/2009, destaque nosso) 
Para completar a situação de penúria, ainda pior que a dos arrozeiros irem à falência, o enunciador mostra que os funcionários demitidos, dificilmente, teriam condições de sobreviver dignamente sem o trabalho que desenvolviam nas terras. $\mathrm{O}$ problema ainda se agravava porque os arrozeiros não tinham perspectivas de encontrar outra área semelhante:

Os problemas não se resumem apenas aos itens já citados. O casal Barili ainda não encontrou outra área para plantar, o arroz estocado está acabando e os funcionários estão sendo demitidos. "Estamos sem terra e não identificaram outra área para nós produzirmos. $O$ arroz que tenho estocado não dá para trabalhar até dezembro, vai acabar antes, então eu queria perguntar às autoridades o que é que vamos fazer", desabafou."

(Folha de Boa Vista, 12/05/2009, destaque nosso)

A repórter enfatizou, por meio de suas construções verbais, que os arrozeiros eram vítimas tanto da desintrusão, uma ação política, quanto de intempéries da natureza.

Entendemos que os índios são, em geral, vistos (por meio da construção do imaginário popular) sob duas principais perspectivas: de um povo sem voz que merece ser cuidado e de um grupo lutador, em busca de seus direitos. Entretanto, a segunda imagem foi apresentada com maior veemência, como no fragmento do texto $n^{\underline{o}} 02$, de 19/03/2009. 
O coordenador-geral do Conselho Indígena de Roraima, José Dionito de Souza, acha improvável que o Supremo Tribunal Federal (STF) mude o placar que mantém a homologação contínua da Terra Indígena Raposal Serra do Sol, mas enfatizou que independente do resultado do julgamento se pela manutenção ou não da área contínua, os índios vão ocupar as fazendas de arroz...

Vamos ocupar a terra, porque não existe fazenda lá, mas sim invasão. Vamos manter a Raposa Serra do Sol em área contínua, seja lá que decisão for o resultado do Supremo Tribunal Federal, não vamos abrir mão da área contínua, afirmou."

(Folha de Boa Vista, 19/03/2009, destaque nosso)

O texto mostrou que, independentemente, do desfecho do julgamento da ação do decreto do STF, que colocaria fim à demarcação em área contínua, ali estariam eles [os índios] prontos para continuar na luta pela terra. Dito de outra maneira, a intenção do enunciador foi não só mostrar que os indígenas estavam ansiosos pelo desfecho do julgamento, mas também decididos a permanecer na reserva (não vamos abrir mão), como já vinham fazendo.

Amenizando o conflito e a representação dos índios, como invasores dispostos a chegar às últimas consequências, o texto seguinte constrói a noção do índio aculturado, adaptado, sem conflitos de identidade e com demandas típicas da sociedade capitalista, que vende o excedente com margem de lucro: 
Abel Barbosa informou que essa não é a realidade, que os indígenas da área em litígio não vivem mais assim. "Somos aculturados, temos filhos estudando na cidade, fazendo faculdade. Queremos o desenvolvimento, não vivemos isolados. A gente quer criar, plantar, comprar e vender gado, produzir", defendeu o tuxaua. "

(Folha de Boa Vista, 20/03/2009, destaque nosso)

Esses exemplos, embora em pouca quantidade, são suficientes para mostrar que, num primeiro momento, seus enunciadores buscaram construir um discurso em que índios e arrozeiros são igualmente vítimas e merecedores de apoio da opinião pública. No entanto, outros registros mostraram que os índios, habitualmente representados como subordinados ao poder político e econômico dos brancos, receberam outra imagem dentro do jornal: são bem informados sobre o tema, a ponto de utilizar esse discurso, por vezes ensaiado, para participar de fóruns de discussão e estão dispostos a chegar às ultimas consequências para lutar pela permanência nas terras. Pode-se supor que os índios foram representados como fortes em oposição aos fracos, os arrozeiros, que precisariam do apoio dos demais setores da sociedade roraimense, entre eles, dos donos do jornal.

\section{Conflito}

A Terra Indígena Raposa Serra do Sol, vale repetir, há muito tempo foi objeto de disputa entre índios e não-índios. O conflito apresentado pela FBV ora foi entre índios com opiniões diferentes, ora entre polícia e índios, ora entre polícia e arrozeiros e ora entre arrozeiros e índios. Nas 23 reportagens, a palavra conflito foi empregada 
19 vezes. O verbo ocupar ou o substantivo ocupação, por sua vez, foram usados em dez oportunidades.

O texto $n^{\circ} 01$, de 28/01, seguramente foi um dos que mais apresentaram este embate. No título, a repórter anuncia: Índios ocupam prédio da Funai e mantêm o administrador refém durante seis horas. No corpo do texto, percebemos que a repórter não mediu esforços para passar ao leitor a tensão do clima vivenciado. Isso pode ser explicado porque em outros trechos, que por motivo de economia não foram aqui reproduzidos, observamos que o enunciador esteve durante boa parte do tempo na sede da Fundação Nacional do Índio (FUNAI) e não só relatou, como também viveu parte da ocupação/ invasão:

Cerca de 200 indios contrários à demarcação da terra indígena Raposa Serra do Sol em área contínua invadiram na tarde de ontem a sede da Fundação Nacional do Índio (FUNAI) e fizeram refém Petrônio Laranjeira, administrador substituto do órgão.

(Folha de Boa Vista, 28/01/2009, destaque nosso)

No trecho a seguir, observamos a manifestação de um autor-criador. O conceito, apresentado por Bakhtin (2009, p. 38), nos diz que é esse elemento que dá forma a um objeto estético, o pivô que sustenta a unidade do todo esteticamente consumado. Esse autor olha os fatos com simpatia ou antipatia, distância ou proximidade, reverência ou crítica, gravidade ou deboche, aplauso ou sarcasmo, alegria ou amargura, generosidade ou crueldade, júbilo ou melancolia. A forma detalhada de dizer como os indígenas estavam armados revelou traços de proximidade. $\mathrm{O}$ sentido produzido foi de que, 
a qualquer instante, o refém poderia ser atingido e o conflito ter um desfecho mais trágico:

Estavam armados com arcos, flechas e bordunas (pedaços de madeira). Ao tomar o prédio, eles esvaziaram as salas, mas mantiveram Laranjeira em cárcere privado por seis horas. A ideia era encarcerar $o$ administrador Gonçalo Teixeira, que está de férias.

(Folha de Boa Vista, 28/01/2009, destaque nosso)

Naquele momento, quando tinham um refém sob seu poder, eram os indígenas que tinham maior domínio, apesar de suas armas serem consideradas mais frágeis.

Logo que chegaram, os indígenas impuseram suas condições. Exigiram que o administrador substituto entrasse em contato com a presidência da Funai, em Brasília, e informasse a situação de invasão. Ao mesmo tempo, condicionaram a liberdade de Laranjeira a 60 passagens aéreas com destino à Capital Federal."

(Folha de Boa Vista, 28/01/2009, destaque nosso)

Os verbos impor, exigir e condicionar reforçam a ideia de que os indígenas estavam no controle da situação. É importante dizer ainda que, na maioria dos textos, quando a palavra conflito foi empregada, esteve quase sempre relacionada 
aos indígenas, sugerindo que eram eles os que desejavam resolver os impasses por meio da força.

O conflito de índio contra índio ainda foi descrito de maneira dramática no texto no 02, como sugere o subtítulo: O tuxaua do Flexal, Abel Barbosa, diz que vai ter briga de indio contra índio e derramamento de sangue.

No corpo do texto, um tuxaua respondeu a outra matéria publicada no dia anterior, no qual um líder indígena tinha dito qual destino daria aos quase dois milhões de terra.

Se eu chegar na sua casa e querer mandar, a senhora não vai aceitar, né? Assim também vai ser com a gente. Ele (Dionito) quer ser o governador da Raposa, vai querer mandar, mas não será do jeito que ele está pensando. Vai ter briga de índio contra índio, vai ter derramamento de sangue, porque a gente não vai aceitar isso", disse Abel Barbosa, de Brasília, no intervalo do julgamento no STF.

(Folha de Boa Vista, 19/03/2009, destaque nosso)

Acreditamos que o clima de tensão e conflito de fato existiu durante o processo final de desintrusão. Apesar disso, pensamos que essa temática, anunciada pelo jornal, exagerou no sensacionalismo, mecanismo utilizado pelos veículos para chamar a atenção dos leitores. É fato que notícias sobre catástrofes, acidentes despertam o interesse do público, causando comoção. Por isso, os momentos em que de fato havia conflitos não foram desperdiçados, ao contrário, foram bastante divulgados. 


\section{Reforço às tradições $\mathrm{x}$ desenvolvimento: da parixara ao forró}

O convívio entre seres humanos pertencentes a esse ou àquele povo dá origem ao conceito de cultura. Dentro de uma realidade econômica, região, ou grupo político características peculiares desses grupos são construídas e consolidadas. Vannucchi (1999, p. 21) acredita que se pode conceituar cultura como autorrealização da pessoa humana no seu mundo. Algo que não se cristaliza apenas no campo teórico, mas também no da sensibilidade, ação e comunicação. Quando se procura extrair dessa realidade o conceito único de cultura surge a dificuldade. É certo que o que se pretende aqui não é polemizar sobre o conceito de cultura, pois sabemos da polissemia que o permeia e, ainda, que o significado equivalente não existe em boa parte das línguas orais e sociedades pesquisadas por etnólogos (Cuche, 1999, p. 15), mas apenas entender os significados intimamente ligados à tradição.

Compreendemos que a cultura reúne um conjunto de sistemas de signos e significados criados pelos grupos sociais. Dessa forma, interpretar as culturas significa interpretar símbolos, mitos, ritos. Guareschi (2002, p. 16) afirma que é no campo da cultura que se percebe a importância dos meios de comunicação, pois são indispensáveis não só para a criação, mas também para a transmissão dos símbolos e ritos. As tradições indígenas, como danças típicas e o uso de objetos artesanais, foram, em vários momentos, destacados no discurso da Folha de Boa Vista. Entretanto, o que chamou a atenção é que em alguns textos o desejo de haver desenvolvimento esteve praticamente lado a lado com elas. Cuche (1999, p. 136) esclarece que nenhuma cultura existe em estado puro, sem jamais ter sofrido influências externas. Dessa maneira o grau de aculturação é um fenômeno praticamente impossível de ser barrado, existe em maior ou menor grau, como observaremos nos próximos exemplos. 
O interessante nos textos é ver não só a oposição tradições $x$ desenvolvimento, mas a crítica implícita nas palavras do enunciador, como no texto $\mathrm{n}^{\mathrm{o}} 02$. A repórter que esteve na Vila Surumu, uma das entradas da Raposa Serra do Sol, conferiu de perto como estavam as manifestações durante o julgamento em área contínua.

Os indios abriram as comemorações pelo retorno do julgamento com uma oração, seguida de ritos tradicionais, na quadra de esportes situada na vila. Dançaram a Parixara com rostos pintados e confeccionaram com palhas utensílios domésticos [...]. Ao final do dia, quando ainda era lido o voto do ministro Marco Aurélio, fizeram uma procissão seguida de vigília por um resultado favorável aos seus pleitos. Posteriormente o forró ocupou o espaço."

(Folha de Boa Vista, 19/03/2011, destaque nosso)

Os ritos tradicionais foram dançados em uma quadra de esporte, lugar que não faz parte da cultura original dos indígenas. De rostos pintados, produziram artesanato, como se quisessem reforçar, materialmente, as tradições que estavam sob ameaça. A marca da crítica ficou por conta da última frase do parágrafo, na qual se afirmou implicitamente e sem nenhum elemento de ligação com a oração anterior, que o forró, dança dos brancos, ocupou, com espontaneidade, o lugar da parixara, típica dos índios. Ou, em outras palavras: que, dependendo das circunstâncias e dos interesses, os índios, uma das últimas comunidades autênticas, como sugere Martín-Barbero, ora praticam uma coreografia, ora outra, sem qualquer crise identitária, resultando na espetacularização e subordinação da sua cultura à modernidade. 
No final do texto no 03 são os indígenas que reforçam a ideia de desenvolvimento. Um tuxaua, contrário à demarcação contínua, reclamava da decisão do STF, que não teria ouvido os interessados para deferir o processo. Ele mesmo destaca que muitos já não vivem mais isolados, como os Yanomami, outra etnia.

Segundo o tuxaua, os ministros votaram sem ouvir todos os segmentos, em especial aqueles que discordam da área contínua, acreditando que os moradores da Raposa/Serra do Sol ainda vivem como os yanomami, que moram no meio da mata e sobrevivem da caça e pesca. Abel Barbosa informou que essa não é a realidade, que os indígenas da área em litígio não vivem mais assim. 'Somos aculturados, temos filhos estudando na cidade, fazendo faculdade. Queremos o desenvolvimento não vivemos isolados. A gente quer criar, plantar, comprar e vender gado, produzir', defendeu o tuxaua."

(Folha de Boa Vista, 20/03/2011, destaque nosso)

O tuxaua Abel Barbosa reivindica aqui o direito de lutar, ter acesso ao que ele considera desenvolvimento: plantar, comprar e vender produtos para estabelecer uma relação de oferta e procura e, ainda, lucro. Afinal os índios não vivem mais isolados, fazem parte não de uma comunidade, como apresentada por Bauman ${ }^{1}$ e sim de uma sociedade, supostamente com mais possibilidades de crescimento econômico. 
Os integrantes do CIR, que até o voto do presidente do Supremo, ministro Gilmar Mendes, estavam dormindo em redes ou sentados conversando na frente de suas casas aguardando a decisão, retomaram as comemorações iniciadas na quarta-feira, quando o julgamento da legalidade da demarcação foi retomado. Eles vestiram roupas tradicionais e dançaram o Parixara, sob o olhar atento dos agentes federais. Um deles carregava uma bandeira com o mapa da Raposa Serra do Sol. Eles ainda mataram um boi e fizeram churrasco. Mas a comemoração mesmo, segundo eles, deve ocorrer no dia 19 de abril, Dia do Índio."

(Folha de Boa Vista, 20/03/2009, destaque nosso)

No mesmo texto, o enunciador mostrou outro contraste. Na vila Surumu, no meio da Terra Indígena, havia tecnologia, pois os não-índios assistiam ao desenrolar do processo de desintrusão em uma TV por assinatura.

Cerca de 20 habitantes não-índios também choraram ao saber que terão que sair da reserva. Eles acompanharam o julgamento do STF por meio de uma TV por assinatura. Ao final se abraçaram, choraram, rezaram e reafirmaram que só deixarão suas casas quando forem reassentados e receberem indenização prévia e de justo valor.

(Folha de Boa Vista, 20/03/2009, destaque nosso) 


\section{Considerações finais}

A partir desses exemplos, já podemos começar a concluir que nem enunciadores, nem a própria redação do jornal FBV, que publicou as reportagens, soube diferenciar a identidade e a cultura dos índios das dos não-índios. Os próprios indígenas, por sua vez, parecem não saber resolver o conflito entre tradição e ruptura, entre natureza e cultura (ou progresso). Talvez seja esse o grande problema da cultura indígena que acabou manifestado nas reportagens selecionadas: não negar as tradições e, ao mesmo tempo, acompanhar as inovações tecnológicas, sob pena de exclusão social, econômica e política.

O jornal apresentou um índio em conflito. De um lado, assistia à TV a cabo para acompanhar a votação em Brasília e falava em desenvolvimento e, do outro, um povo que fazia danças típicas, produzia artesanato, mas que também dançava forró.

As representações dos indígenas oscilaram de acordo com o contexto que os cercavam. Ora era interessante parecer ainda mais índio, ora era conveniente falar em desenvolvimento, lançar no grupo o desejo pela autossustentação. De fato, hoje em dia, praticamente aculturados e com tamanho contato com o homem branco, essas contradições seriam inevitáveis. Mas é importante enfatizar que quando o índio é apresentado de forma estereotipada esse discurso está nas palavras do enunciador do jornal. Em quase todas as situações analisadas, na qual havia indícios da cultura indígena, o jornal fazia questão de destacá-la. Já a busca do desenvolvimento está nos enunciados proferidos pelos próprios índios, como se quisessem responder à fala do enunciador.

Também observamos, que a Folha de Boa Vista, no que diz respeito a índios e arrozeiros, deu igual abertura de espaço aos dois grupos sociais. No entanto, enquanto na maior parte a representação dos índios foi de luta e sujeitos agressivos, a dos rizicultores foi de homens injustiçados, que precisavam do jornal para tornar públicos seus pensamentos. 
Acreditamos também que a tentativa de vitimizar os arrozeiros serviu como pano de fundo para que a população se compadecesse; afinal, a maior economia do Estado estava sendo abalada. Dessa forma, muitas pessoas seriam afetadas e indiretamente não seriam simpatizantes à luta dos indígenas. Isso quer dizer que, ainda que de maneira implícita, a FBV deu apoio aos rizicultores.

Mas, ao final e ao cabo, o que a FBV mostrou é que, além de fazer questão de reforçar o poder que tem para tornar públicas as informações, quis convencer os leitores de sua credibilidade. Por fim, reforçamos, por meio desses exemplos, o conceito de palavra para Bakhtin: que ela "[se] constitui como produto ideológico, ou seja, é resultado de um processo de interação" (Stella apud Brait, 2005, p. 178).

\section{REFERÊNCIAS}

BAKTHIN, Mikhail. Marxismo e filosofia da Linguagem: problemas fundamentais da linguagem. 13. ed. São Paulo: Hucitec, 2009. . Estética da criação verbal. São Paulo: Martins Fontes, 2003.

BAUMAN, Zygmunt. Comunidade: A busca por uma segurança no mundo atual. Trad. Plínio Dentzien. Rio de Janeiro: Jorge Zahar, 2003.

BOURDIEU, Pierre. Sobre a televisão. Rio de Janeiro: Jorge Zahar, 1997.

BRAIT, Beth. O texto mostra a língua, costura e descostura discursos. Revista de Filologia e Linguística Portuguesa, São Paulo, v. 3, Humanitas, 2007.

COTTA, Pery. Jornalismo: Teoria e prática. Rio de Janeiro: Livraria e Editora Rubio, 2005.

CUCHE, Denys. A noção da Cultura nas ciências sociais. Bauru: EDUSC, 1999.

FERREIRA, Júnior José. Capas de jornal. São Paulo: Senac, 2003.

FIORIN, José Luiz. Introdução do pensamento de Bakhtin. São Paulo: Ática, 2008.

GUARESCHI, Pedrinho A. Comunicação: Controle Social. Petrópolis: Editora Vozes, 2002.

LARAIA, Roque de Barros. Cultura: um conceito antropológico. 23. ed. Rio de Janeiro, 2009.

LIMA, Maria Goretti Leite de. O índio na mídia impressa em Roraima. Boa Vista: Editora UFRR, 2008. 
LIMA, Vanessa. Índios ocupam prédio da Funai e mantêm administrador refém durante seis horas. Folha de Boa Vista, 28/01/2009.

Sodiur alerta para conflito entre índios. Folha de Boa Vista, 20/03/2009.

MARTÍN-BARBERO, Jesús. Dos meios às mediações: comunicação, cultura e hegemonia. Rio de Janeiro: Editora UFRJ, 2003.

SANTOS, Andrea Paula dos, 2005. Trajetórias da História Social e da Nova História Cultural: cultura, civilização e costumes no cotidiano do mundo do trabalho. Disponível em: <http://www.fef.unicamp.br/sipc/anais9/ artigos/mesa_debates/art3.pdf>. (IX Simpósio Internacional Processo Civilizador - Tecnologia e Civilização, 2005, Ponta Grossa. Anais do IX Simpósio Internacional Processo Civilizador - Tecnologia e Civilização, 2005. V. 1.) Acesso em: 24 nov. 2011.

STELLA, Paulo. In: BRAIT, Beth. Bakhtin: Conceitos-chaves. 4. ed. 3ª reimpressão. São Paulo: Contexto, 2005. TRAJANO, Andrezza. Suspensão temporária de julgamento não acirra ânimos em Surumu. Folha de Boa Vista, 19/03/2009.

. Produtora diz que multa levará à falência. Folha de Boa Vista, 12/05/2009.

VANNUCCHI, Aldo. Cultura Brasileira: O que é, como se faz. São Paulo: Edições Loyola, 1999.

ZANCHETTA, Juvenal. Imprensa escrita e telejornal. São Paulo: UNESP, 2006.

\section{NOTA}

1 Zygmunt Bauman, sociólogo polonês e teórico sobre identidade, parte da mitologia grega para afirmar que o sentimento de comunidade é o ponto de partida de determinado povo. Em comunidade as pessoas não precisam explicar o que falam, pensam ou como agem. Ou seja, "dentro do círculo aconchegante elas não precisam provar nada e podem, o que quer que tenham feito, esperar simpatia e ajuda" (Bauman, 2003 p. 16). É aconchegante permanecer dentro da comunidade. No entanto, este círculo pode ser aberto por outras culturas. Essa fissura, como argumentou o teórico, surge com o aparecimento da informação, independente de quem a leva. 